
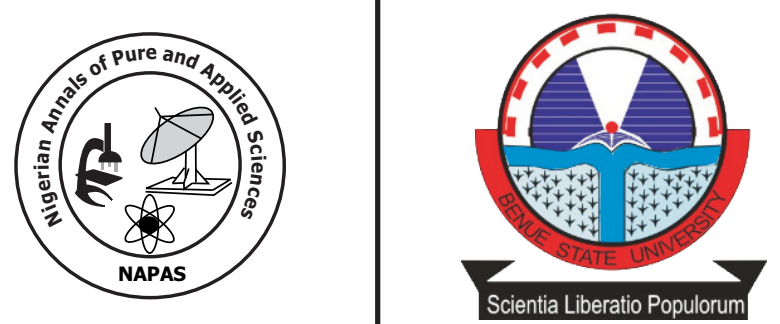

\title{
Evaluation of Growth of Toxigenic Strain of Aspergillus flavus on Turmeric-Based Media at Different Water Activities
}

\author{
Uteile, F.R., Godwin-Egein, M.I. and Okereke, V. C.* \\ Department of Crop and Soil Science, \\ University of Port Harcourt, \\ Choba, PMB 5323, Port Harcourt, Nigeria. \\ *Corresponding Author:chykeoky@yahoo.com
}

\section{Abstract}

Climatic conditions of the rain forest ecological zone of Nigeria favour the growth of Aspergillus flavus and subsequent aflatoxin production. This study was carried out to investigate the effect of water activity $\left(0.85,0.9,0.95,0.98\right.$ and $\left.0.995 \mathrm{a}_{\mathrm{w}}\right)$ on the lag phase prior to growth and mycelial growth of a toxigenic strain of $A$. flavus on turmeric-based media at $28 \pm 2^{\circ} \mathrm{C}$ after 12 days incubation period. Four different varieties; UT14, UT25, UT35 and UT46 obtained from National Root Crop Research Institute (NRCRI), Abia State and used in the preparation of the different media. A toxigenic strain of $A$. flavus isolated from turmeric in Port Harcourt was used in the experiment. The experiment was a $5 \times 4$ factorial laid out in completely randomized design (CRD), replicated three times. Results showed that regardless of the variety, no growth was observed at $0.85 \mathrm{a}_{\mathrm{w}}$ at 12 days of incubation. The shortest lag phase prior to growth was obtained at $0.995 \mathrm{a}_{\mathrm{w}}$ and the longest obtained at $0.90 \mathrm{a}_{\mathrm{w}}$. Optimal growth was observed at $0.98 \mathrm{a}_{\mathrm{w}}$ in three varieties (UT14, UT25and UT46), UT35 had marginal optimal growth at $0.995 \mathrm{a}_{\mathrm{w}}$. Minimal growth of the A. flavus strain was obtained at $0.90 \mathrm{a}_{\mathrm{w}}$ at $28 \pm 2^{\circ} \mathrm{C}$ in all varieties. This result could be useful in the storage of turmeric, as this food product could be stored at moisture content of $<85 \%$.

Key words: Toxigenic, Aspergillus flavus, Lag phase, Strain, Turmeric, Water activity 


\section{Introduction}

Contamination of food products with Aspergillus flavus can occur during production, storage, processing, transportation or marketing (Bankole et al., 2006). This could have great effect on the quality of the products. In addition to the colonization of food products, many strains of fungal specie can produce significant quantities of aflatoxin which, when consumed are toxic to mammals (Agrios, 2005). The incidence of this fungus increases in the presence of insects (Adedire, 2001) and some types of stress such as drought, temperature (Craufurd et al., 2006; Kebede et al., 2012) and poor storage condition.

Generally, excessive moisture conditions and high temperatures of storage increase the occurrence of $A$. flavus and subsequent aflatoxin production. Key ecological factors of water activity $\left(\mathrm{a}_{\mathrm{w}}\right)$ and temperature influence the colonization of food commodities by spoilage fungi (Magan et al., 2010; Akbar and Magan, 2014). Studies have shown that under high temperature stress when combined with drought conditions, higher amounts of aflatoxins are produced by A. flavus (Jone et al., 1980; Payne et al., 1988; Craufurd et al., 2006; Kebede et al., 2012). The combination of high temperature and water stress in some regions of the world could increase the contamination of mycotoxigenic fungi in major commodities and thus becomes a serious problem in food security and food nutritional quality worldwide (Magan et al., 2011). Large amount of turmeric are being wasted annually due to poor post-harvest handling which results to fungal colonization and subsequent toxin contamination, thus making the products unfit for human consumption. The level of fungal mycelial growth is influenced by the level of water activity and temperature of the store (Cairns et al., 2005; Pardo et al., 2006; Akbar and Magan, 2014), thus the need to determine the optimum water activity for growth of A. flavus on turmeric. The objective of the study was therefore to evaluate the effect of storage moisture conditions at $28 \pm 2^{\circ} \mathrm{C}$ on the lag phase prior to growth and growth of a toxigenic strain of Aspergillus flavus on different varieties of turmeric used as media.

\section{Materials and Methods}

The experiment was carried out at the Department of Crop and Soil Science Laboratory, University of Port Harcourt, Nigeria $\left(6.55^{\circ} 0.2^{\prime} \mathrm{N}\right.$ latitude, $4.54^{\circ} 10.02^{\prime} \mathrm{E}$ longitude). Four (4) varieties of turmeric $\{$ UT46 (high yielding), UT14 (moderate yielding) and UT25 and UT35 (low yielding) $\}$ were obtained from the National Root Crop Research Institute (NRCRI), Umudike, Nigeria, and used for the experiment. The samples were cleaned, chopped into pieces, air dried, ground into powder and stored properly. A toxigenic strain of Aspergillus flavus confirmed using Coconut agar medium (CAM) (Lin and Dianese, 1976) was used in the experiment. The $A$. flavus strain was maintained on Malt Extract Agar (MEA) medium. A standard medium of $2.5 \%$ milled turmeric agar $(25 \mathrm{~g}$ of tumeric powder +10 $\mathrm{g}$ technical agar $+0.16 \mathrm{~g}$ chloramphenicol +1000 $\mathrm{ml}$ of water) of each variety was prepared. The $\mathrm{a}_{\mathrm{w}}$ of the media were modified by adding increasing amounts of glycerol to obtain the following $\mathrm{a}_{\mathrm{w}}$ treatment levels of $0.85,0.90,0.95,0.98$ and 0.995 . These were checked with $\mathrm{a}_{\mathrm{w}}$ meter (Aqualab, Decagon devices, Inc., USA). The media were prepared by autoclaving at $121^{\circ} \mathrm{C}$ for 45 minutes, shaken vigorously prior to pouring 15 $\mathrm{ml}$ into $90 \mathrm{~mm}$ sterile plates when media solidified at $25 \pm 2^{\circ} \mathrm{C}$. $2 \mu 1$ of inocula of each of the $A$ flavus strains previously prepared from 6-days old mycelia $+5 \mathrm{ml}$ sterile water supplemented with $0.05 \%(\mathrm{w} / \mathrm{v})$ Tween 80 were centrally inoculated into each of the plates. Incubation was at $28 \pm 2^{\circ} \mathrm{C}$. Fungal growth assessment was done daily for 12 days; measurement of growth was done in two directions (i.e. horizontal and vertical) at right angles to each other (Marin et al., 1996). Data was used for the determination of lag phase ( $\lambda$ ) in days prior to growth and growth rate $(\mathrm{mm} /$ day). Data was fitted using linear model. Growth rate was calculated from the slope of the regression graph while lag phase by equaling the regression line formula to the original inoculum. Analysis of data was done using Genstat $16^{\text {th }}$ Edition; VSN Industrial Ltd, UK. Comparison of data means was considered at $5 \%$ probability level.

\section{Results}

Regardless of the variety, no growth was observed at $0.85 \mathrm{a}_{\mathrm{w}}$ after 12 days of incubation. The strain of Aspergillus flavus exhibited varying degrees of growth at the different water activity levels. Increased water activity resulted in decrease in the lag phase prior to growth of the fungus. Statistically, the main effect of $a_{w}$, variety and $\mathrm{a}_{\mathrm{w}}$ and variety interaction were all significant $(\mathrm{P}<0.001)$ (Table 1). On the average, the shortest lag phase prior to growth of $A$. flavus in the various media was at $0.995 \mathrm{a}_{\mathrm{w}}(1.2$ days $)$ and the longest at $0.90 \mathrm{a}_{\mathrm{w}}(<0.5$ days) (Fig. 1). Fig. 2 shows that with the exception of UT35, the fungus had optimal growth at $0.98 \mathrm{a}_{\mathrm{w} .}$ Aspergillus flavus on UT35 had 
marginal optimum growth at $0.995 \mathrm{a}_{\mathrm{w}}$. Furthermore, the A. flavus strain exhibited the fastest growth rate on UT14 medium (1 mm/day), followed by UT35 $(0.7 \mathrm{~mm} /$ day $)$, UT46 $(0.6$ $\mathrm{mm} /$ day $)$ and UT25 (0.5 $\mathrm{mm} /$ day) with the least growth rate.

Table 1: P values for the lag phase (?? days) and growth rate of A. flavus strain on turmeric-based media at different water activities $\left(\mathrm{a}_{\mathrm{w}}\right)$

\begin{tabular}{lcc}
\hline Parameter & Lag phase & Growth rate \\
\hline Variety & $<0.001^{* * *}$ & $<0.001^{* * *}$ \\
Water activity $\left(\mathrm{a}_{\mathrm{w}}\right)$ & $<0.001^{* * *}$ & $<0.001^{* * *}$ \\
Variety $\mathrm{x} \mathrm{a}_{\mathrm{w}}$ & $<0.001^{* * *}$ & $<0.001^{* * *}$ \\
\hline
\end{tabular}

*** = very highly significant.
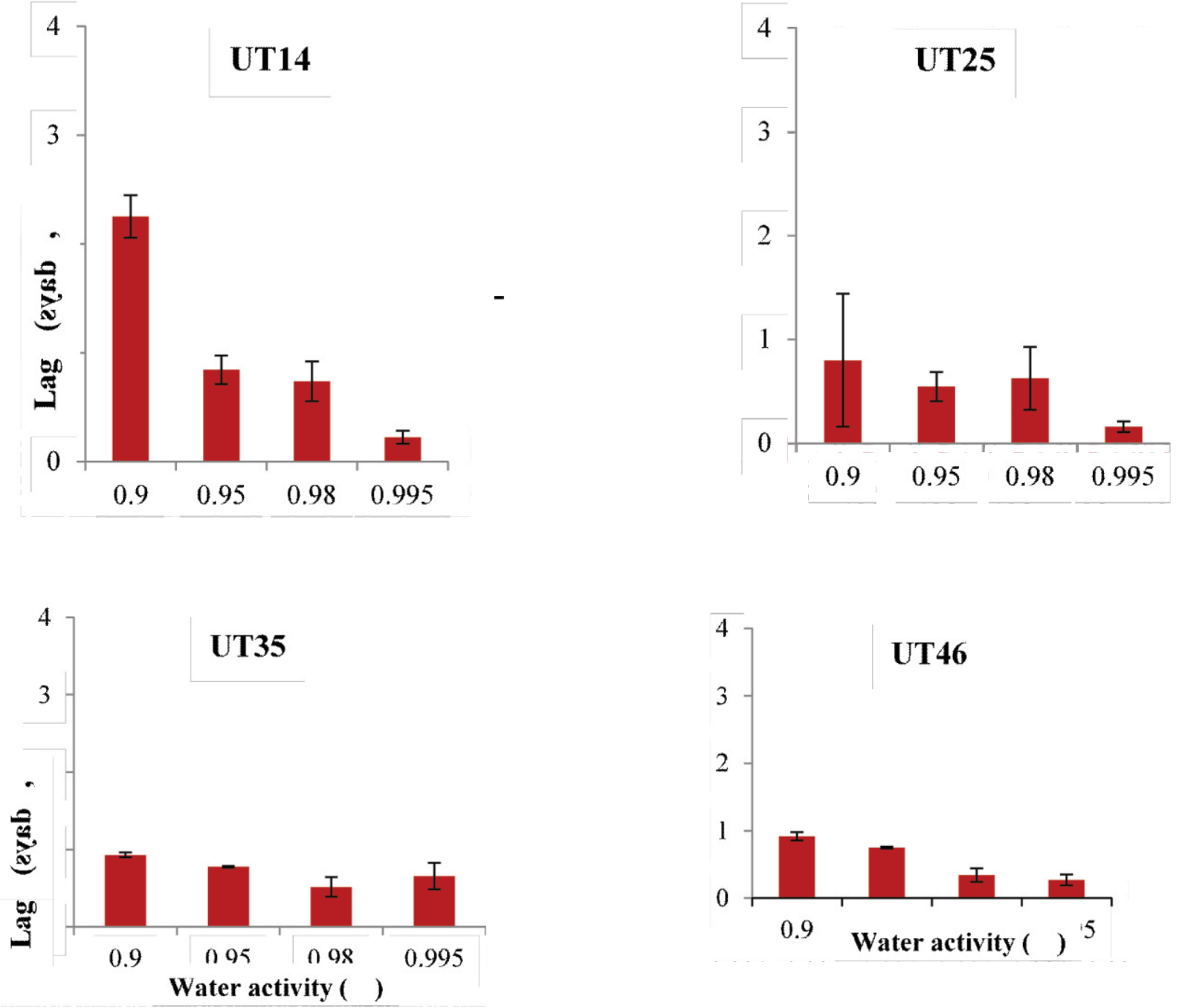

Figure 1: Effect of different water activities ( $\left.\mathrm{a}_{\mathrm{w}}\right)$ on the lag phase prior to growth strain of A. flavus on turmericbased media at $28 \pm 2^{\circ} \mathrm{C}$ after 12 days of incubati
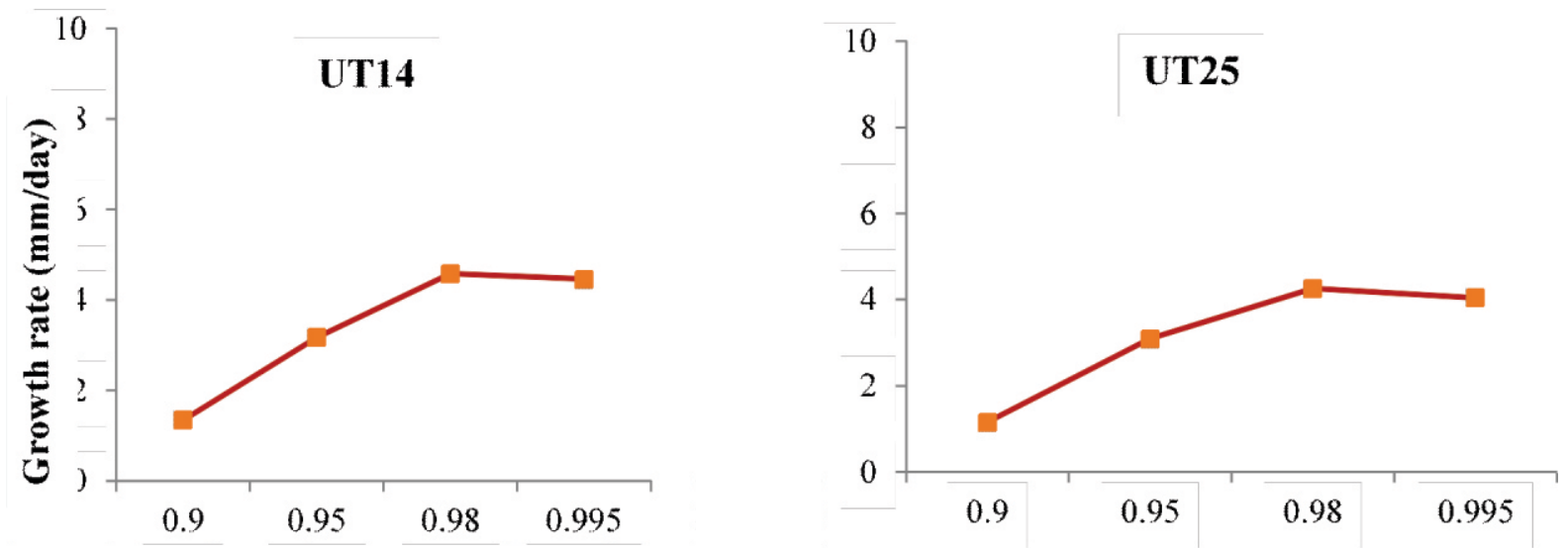

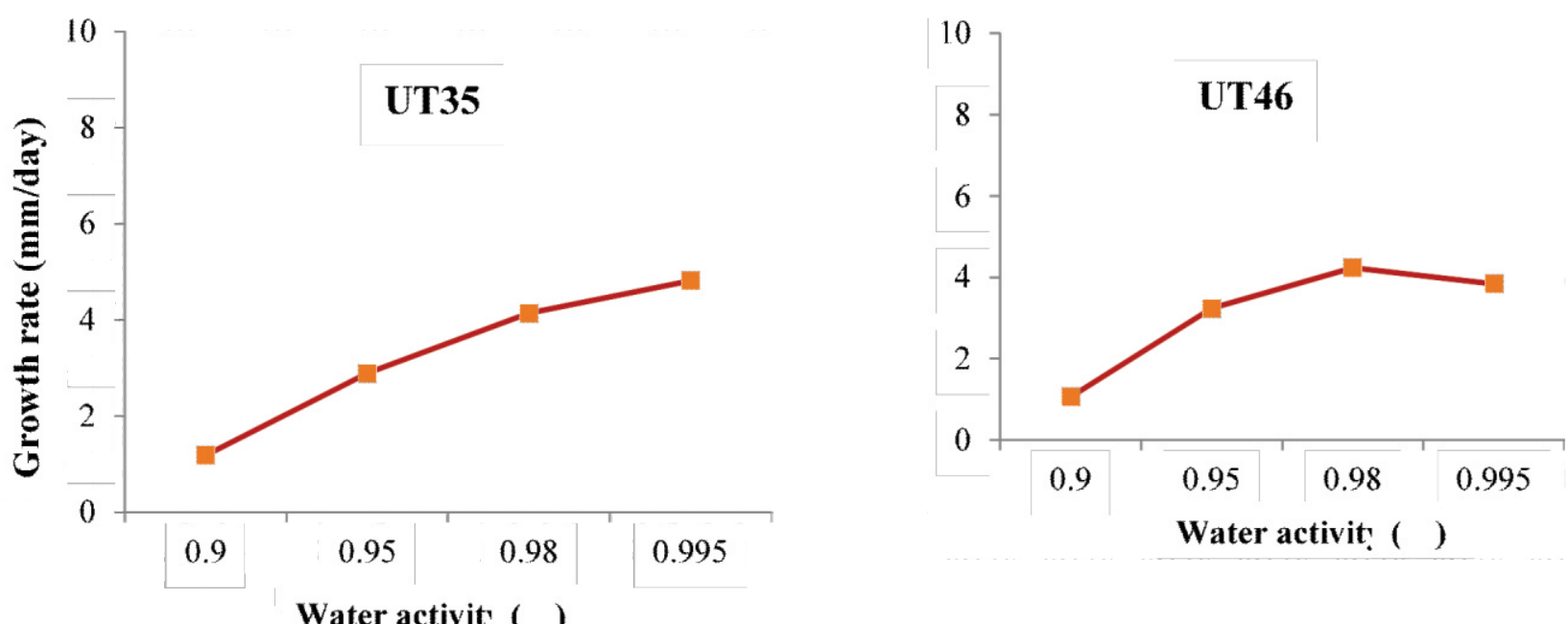

Figure 2. Effects of different water activities $\left(\mathrm{a}_{\mathrm{w}}\right)$ on the g rowth rates of A. flavus on turmeric-based media at $28 \pm 2^{\circ} \mathrm{C}$ after 12 days of incubation.

\section{Discussion}

The present study investigated the growth of a toxigenic strain of $A$. flavus on different varieties of turmeric used as growth media. A. flavus could grow on turmeric-based media at $28 \pm 2^{\circ} \mathrm{C}$. Jeswal $\&$ Kumar (2014 and 2015) reported the occurrence of Aspergillus spp in both stored ginger and turmeric samples. Rawat et al. (2014) also found that A. niger, A. flavus, Mucor and Rhizopus species were the dominant mycoflora in sampled spices including ginger and turmeric. The strain of A. flavus used in the current study was not able to grow at $0.85 \mathrm{a}_{\mathrm{w}}$ at $28 \pm 2^{\circ} \mathrm{C}$ over the 12 day incubation period and this is in line with the findings of some authors. Akbar and Magan (2014) reported no growth $A$. flavus at a water activity level of $0.85 \mathrm{a}_{\mathrm{w}}$ regardless of the temperature, while Labouar et al., (2016) observed no growth of A. flavus at $0.85-0.88 \mathrm{a}_{\mathrm{w}}$ at $15-37^{\circ} \mathrm{C}$. Also Akbar and Magan (2014) reported lag phase prior to growth of Aspergillus spp at $<1$ day at $0.95-0.98$ and $25-37^{\circ} \mathrm{C}$ and optimum growth at $0.98 \mathrm{a}_{\mathrm{w}}$ at $30-35^{\circ} \mathrm{C}$. Their result is similar to that obtained from this study. The current finding has revealed that the different varieties of turmeric could react differently to the growth of $A$. flavus at the various water activity levels. These differences could be attributed to the difference in genotype. The result also points to the fact that the growth of the toxigenic strain of A. flavus was optimal at $0.98 \mathrm{a}_{\mathrm{w}}$, although this needs to be validated in vivo. Generally, A. flavus was able to grow over a wider range of $\mathrm{a}_{\mathrm{w}}$ levels and appears to be tolerant of drier condition $\left(0.90 \mathrm{a}_{\mathrm{w}}\right)$. The implication is that under drought stress occasioned by climate change, there could be high colonization of turmeric by toxigenic strains of $A$. flavus with variation in optimum conditions of on turmeric varieties. The mycelial prediction of $A$. flavus at different $\mathrm{a}_{\mathrm{w}}$ levels and incubation temperature employed in the study might be useful in the determination appropriate conditions for drying and storage of turmeric to prevent aflatoxin contamination.

\section{Conclusion}

The findings from the current study explain the effect $\mathrm{a}_{\mathrm{w}}$ could have on the growth and colonization of Aspergillus flavus which could occur during post-harvest handling and storage of turmeric. It showed $A$. flavus grows on turmeric: no growth occurred at $0.85 \mathrm{a}_{\mathrm{w}}$; increased water activity resulted in decrease in the lag phase prior to growth and different varieties of turmeric reacted differently to the growth of A. flavus at the various water activity levels. This information could be used in decision-making process in relation to $\mathrm{a}_{\mathrm{w}}$ during turmeric production and also contribute to optimal strategy selection in the control of aflatoxin contamination in turmeric. Turmeric should be dried immediately after harvest at least below $85 \%$ moisture content level and stored under appropriate conditions in order to minimize contamination with $A$. flavus.

\section{References}

Adedire, C.O. (2001). Biology, Ecology and Control of Insect Pests of Stored Grains. In: Pest of Stored Cereals and Pulses in Nigeria, Ofuya, T.I. and N.E.S. Lale (Eds.). Dave Collins Publications, Nigeria, pp: 5994.

Agrios, G. N. (2005). Plant Pathology: Fifth Edition. Elsevier Academic Press. P.922. ISBN 0-12-044565-4.

Akbar, A. and Magan, N. (2014). The impact of water and temperature interactions on lag phase, growth and potential ochratoxin A 
production by two new species, Aspergillus aculeatinus and $A$. sclerotiicarbonarius, on green coffee-based medium. International Journal of Food Microbiology, 188: 116121.

Bankole, S.S and Adebanjo, A. (2003). Mycotoxins in food in West Africa: Current situation and possibilities of controlling it. African Journal of Biotechnology, 2: 254263.

Cairns-Fuller, V., Aldred, D. and Magan, N. (2005). Water, Temperature and Gas Composition Interactions Affect Growth and Ochratoxin A Production by Isolates of Penicillium verrucosum on Wheat Grain. Journal of Applied Microbiology, 99: 1215-1221.

Craufurd, P.Q., Prasad, P.V.V., Waliyar. F. and Taheri, A. (2006). Drought, Pod Yield, Preharvest Aspergillus infection and aflatoxin contamination on peanut in Niger. Field Crops Research, 98: 20-29.

Jeswal, P. and Kumar, D. (2014). Toxigenic mycofloral association and mycotoxins contamination in turmeric, coriander and red chilli and risk assessment of its effects. American Journal of Biological, Chemical and Pharmaceutical Science, 2: 10.17.

Jeswal, P. and Kumar, D. (2015). Mycobiota and natural incidence of aflatoxins, ochratoxin $\mathrm{A}$, and citrinin in Indian spices confirmed by LC-MS/MS. International Journal of Microbiology, 2015: 1-8.

Jones, R.K., Duncan, H.E., Pay ne, G. A. and Leonard, K. J. (1980). Factors Influencing Infection by Aspergillus flavus in SilkInoculated Corn. Plant Disease, 64: 859863.

Kebede, H., Abbas, H. K., Fisher, D. K., and Bellaloui, N. (2012). Relationship between Aflatoxin Contamination and Physiological Responses of Corn Plants under Drought and Heat Stress. Toxins, 4(11): 1385-1403.

Lahouar, A., Marin, S., Crespo-Sempere, A., Said, S. and Sanchis, V. (2016). Effect of temperature, water activity and incubation time on fungal growth and aflatoxin $B_{1}$ production by toxigenic Aspergillus flavus isolates on sorghum seeds. Revista Argentina Microbiology, 48(1): 78-85.

Lin, M.T. and Dianese, J.C. (1976). A coconutagar medium for rapid detection of aflatoxin production by Aspergillus spp. Phytopathology, 66: 1466-1469.

Magan, N., Aldred, D., Hope, R. and Mitchell, D. (2010). Environmental factor and Interactions with Mycobiota of Grain and Grapes: Effects on Growth, Deoxynivalenol and Ochratoxin Production by Fusarium culmorum and Aspergillus carboarius. Toxins, 2: 353-366.

Magan, N., Medina, A. and Aldred, D. (2011). Possible climate change effect on mycotoxin contamination of food crop preand postharvest. Journal of Plant Pathology, 60: 150-163.

Marín, S., Sanchis, V., Teixido, A., Saenz, R., Ramos, A. J., Vinas, I. and Magan, N. (1996). Water and Temperature Relations and Microconidial germination of Fusarium moniliforme and Fusarium proliferatum from Maize. Canadian Journal of Microbiology, 42(10): 10451050.

Pardo, E., Lagunas, U., Sanchis, V., Ramos, A.J. and Marin, S. (2005). Influences of water activity and temperature on condial germination and mycelia growth of ochrat oxigenic isolates of Aspergillus ochraceus on grape juice synthetic medium. Predictive model. Journal of the Science of Food and Agriculture, 85: 1681 - 1686.

Payne, G., Thompson, D., Lillehoj, E., Zuber, M. and Adkins, C. (1988). Effect of Temperature on the Pre-harvest infection of Maize Kernels by Aspergillus flavus, Phytopathology, 78: 1379-1380.

Rawat, A., Mahajan, S., Gupta, A., Agnihotri, K., Wahi, N. and Sharm, R. (2014). Detection of toxigenic fungi and mycotoxins in some stored medicinal plant samples. International Journal of Applied Science and Biotechnology, 2(2): 211-216. 